\title{
Supporting Information to: \\ Single Etch Patterning of Stacked Silver and Molybdenum Alloy Layers on Glass Using Microcontact Wave Printing
}

\author{
Dirk Burdinski, ${ }^{*}{ }^{\dagger}$ Harold J. A. Brans, ${ }^{\ddagger}$ Michel M. J. Decré ${ }^{\dagger}$
}

${ }^{\dagger}$ Philips Research, Prof. Holstlaan 4, 5656 AA Eindhoven, The Netherlands and

${ }^{\ddagger}$ Philips Applied Technologies, 5600 MD Eindhoven, The Netherlands

RECEIVED DATE (automatically inserted by publisher); Email: dirk.burdinski@philips.com

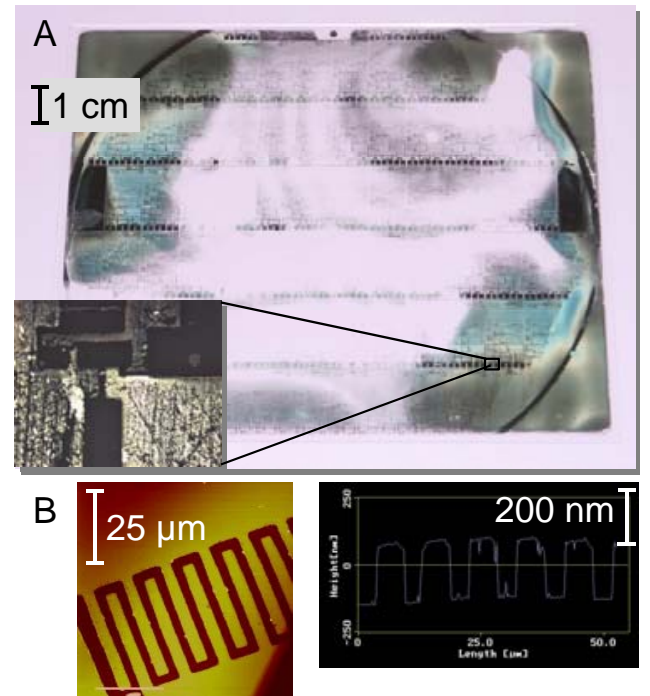

Figure S1. APC/MoCr $(200 \mathrm{~nm} / 20 \mathrm{~nm})$ substrates printed with an inked PDMS stamp (ODT, $2 \mathrm{mM}, 15 \mathrm{~s}$ contact time) and etched with an optimized NPW etchant $\left(\mathrm{HNO}_{3}(65 \%), \mathrm{H}_{3} \mathrm{PO}_{4}(85 \%), \mathrm{H}_{2} \mathrm{O}\right.$ (volume fractions: 3:9:13): (A) Optical micrograph of a $10 \times 15 \mathrm{~cm}^{2}$ substrate (wave printed). (B) AFM picture of a homogeneously etched $1 \times 1 \mathrm{~cm}^{2}$ substrate (manually printed) and corresponding height profile.
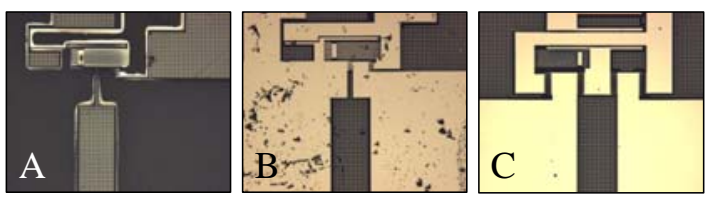

Figure S2. Optical micrograph of a part of an APC/MoCr $(200 \mathrm{~nm} / 20 \mathrm{~nm})$ substrate $\left(10 \times 15 \mathrm{~cm}^{2}\right)$ microcontact wave printed with an inked PDMS stamp (ODT, $2 \mathrm{mM}, 15 \mathrm{~s}$ contact time) and etched with an optimized NPW $\left(\mathrm{HNO}_{3}\right.$ (65\%), $\mathrm{H}_{3} \mathrm{PO}_{4}$ (85\%), $\mathrm{H}_{2} \mathrm{O}$ (volume fractions: 3:9:13)) etchant (A), and with an optimized NTW etchant $\left(\mathrm{HNO}_{3}(65 \%)\right.$, TFA (99\%), $\mathrm{H}_{2} \mathrm{O}$ (volume fractions: 3:9:13); $\mathrm{NaNO}_{2}\left(10^{-3} \mathrm{M}\right)$ without (B) and with added $\mathrm{H}\left(\mathrm{CH}_{2}\right)_{10} \mathrm{SO}_{3} \mathrm{Na}$, (NaDS, $\left.10^{-3} \mathrm{M}\right)(\mathrm{C})$.

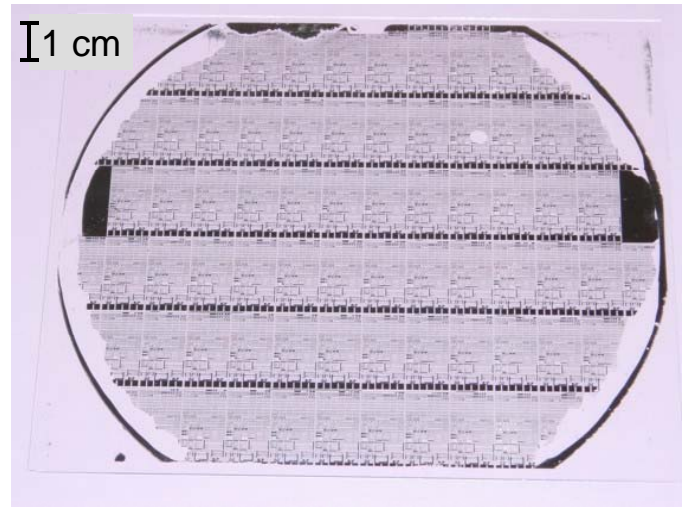

Figure S3. APC/MoCr $(200 \quad \mathrm{~nm} / 20 \quad \mathrm{~nm})$ substrate $\left(10 \times 15 \quad \mathrm{~cm}^{2}\right)$ microcontact wave printed with an inked PDMS stamp (ODT, $2 \mathrm{mM}, 15 \mathrm{~s}$ contact time) and etched with an optimized NTW etchant $\left(\mathrm{HNO}_{3}(65 \%)\right.$, TFA (99\%), $\mathrm{H}_{2} \mathrm{O}$ (volume fractions: 3:9:13); $\mathrm{NaNO}_{2}\left(10^{-3} \mathrm{M}\right)$.

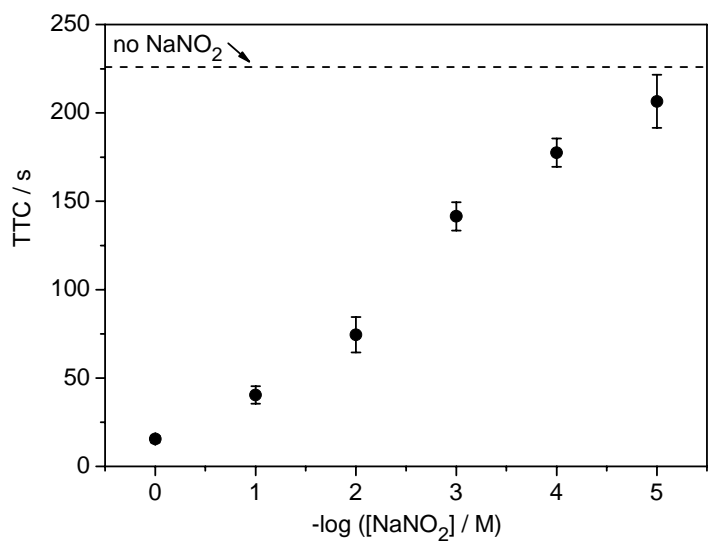

Figure S4. Time to clear (TTC) for the development of a manually printed (ODT, $2 \mathrm{mM}, 15 \mathrm{~s}$ contact time) APC/MoCr $(200 \mathrm{~nm} / 20 \mathrm{~nm}$ ) double layer on $1 \times 2 \mathrm{~cm}^{2}$ glass substrates with an NTW $\left(\mathrm{HNO}_{3}(65 \%)\right.$, TFA $(99 \%), \mathrm{H}_{2} \mathrm{O}$ (volume fractions: 3:9:13)) etchant as a function of the $\mathrm{NaNO}_{2}$ concentration $\left(10^{-5}-1 \mathrm{~mol} / \mathrm{L}\right)$. Etching was performed at room temperature. The clear point was determined by visual inspection. 


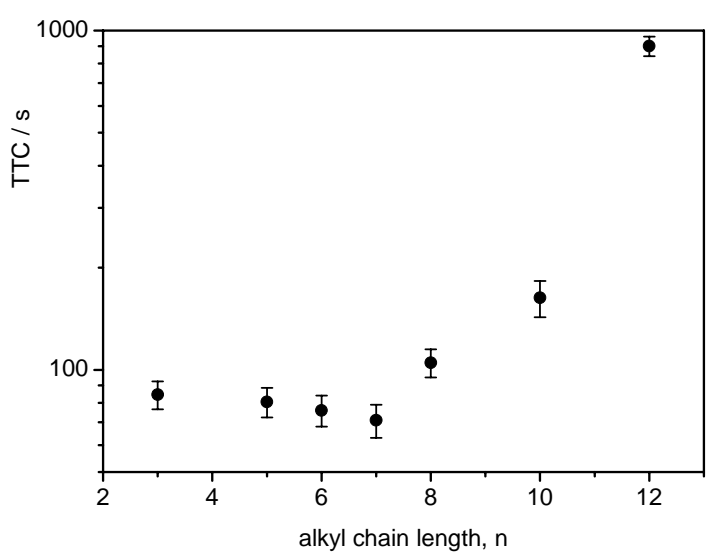

Figure S5. Time to clear (TTC) for the development of a manually printed (ODT, $2 \mathrm{mM}, 15 \mathrm{~s}$ contact time) APC/MoCr $(200 \mathrm{~nm} / 20 \mathrm{~nm})$ double layer on $1 \times 2 \mathrm{~cm}^{2}$ glass substrates with an NTW etching bath $\left(\mathrm{HNO}_{3}(65 \%)\right.$, TFA (99\%), $\mathrm{H}_{2} \mathrm{O}$ (volume fractions: 3:9:13); $\mathrm{NaNO}_{2} \quad\left(10^{-2} \mathrm{M}\right)$; $\left.\mathrm{H}\left(\mathrm{CH}_{2}\right)_{\mathrm{n}} \mathrm{SO}_{3} \mathrm{Na},\left(10^{-3} \mathrm{M}\right)\right)$ as a function of the chain length $\mathrm{n}$ of the alkanesulfonate additive. Etching was performed at room temperature. The clear point was determined by visual inspection.

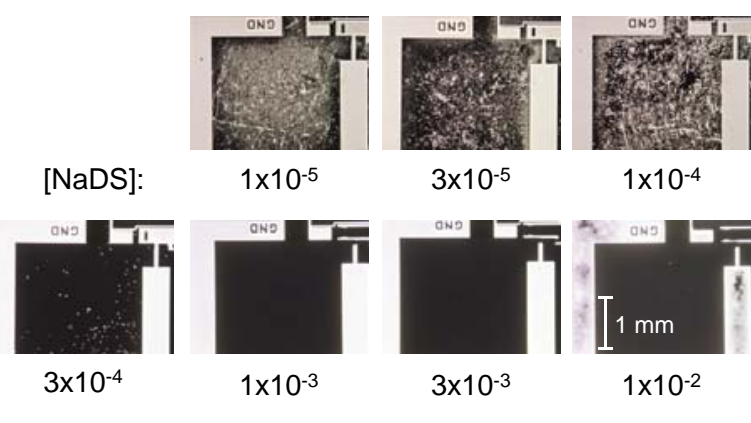

Figure S6. Optical micrographs (backlight transmission) of APC/MoCr $(200 \mathrm{~nm} / 20 \mathrm{~nm})$ on glass substrates microcontact printed with an inked PDMS stamp (ODT, $2 \mathrm{mM}, 15 \mathrm{~s}$ contact time) and etched with an optimized NTW etchant $\left(\mathrm{HNO}_{3}(65 \%)\right.$, TFA (99\%), $\mathrm{H}_{2} \mathrm{O}$ (volume fractions: 3:9:13); $\mathrm{NaNO}_{2}\left(10^{-1} \mathrm{M}\right)$ containing different concentrations of $\mathrm{H}\left(\mathrm{CH}_{2}\right)_{\mathrm{n}} \mathrm{SO}_{3} \mathrm{Na}$, (NaDS) as indicated in $\mathrm{mol} / \mathrm{L}$.
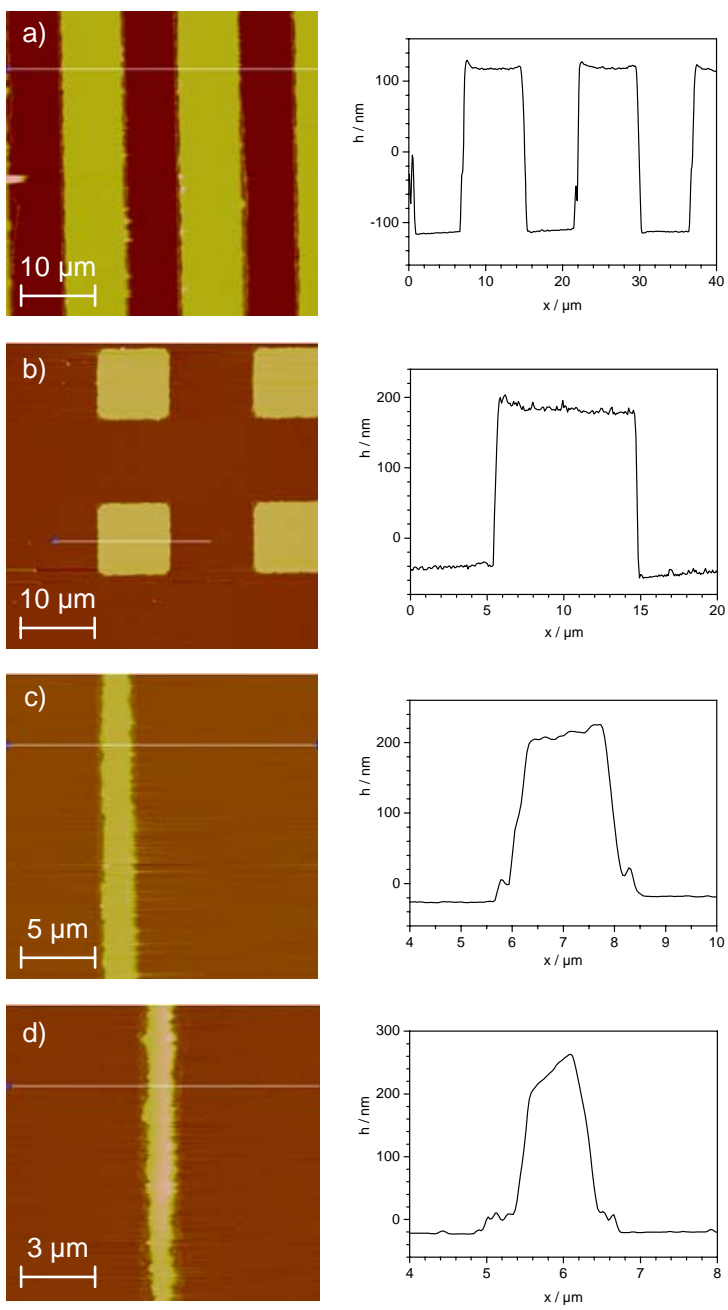

Figure S7. Results from the atomic force microscopic analysis of APC/MoCr $(200 \mathrm{~nm} / 20 \mathrm{~nm})$ on $10 \times 15 \mathrm{~cm}^{2}$ glass substrates microcontact printed with an inked PDMS stamp (ODT, $2 \mathrm{mM}, 15 \mathrm{~s}$ contact time) and etched with an optimized NTW etchant $\left(\mathrm{HNO}_{3}(65 \%)\right.$, TFA $(99 \%), \mathrm{H}_{2} \mathrm{O}$ (volume fractions: 3:9:13); $\mathrm{NaNO}_{2}\left(10^{-1} \mathrm{M}\right) ; \mathrm{H}_{(}\left(\mathrm{CH}_{2}\right)_{\mathrm{n}} \mathrm{SO}_{3} \mathrm{Na},\left(10^{-3} \mathrm{M}\right)$ ). Step height measurements in non-contact (tapping) mode. a) Line patterns with a measured width of the elevated lines of $7.8 \mu \mathrm{m}$ (top) and $8.8 \mu \mathrm{m}$ (bottom) (nominal $9 \mu \mathrm{m}$ ), a pitch of $15 \mu \mathrm{m}$ (nominal $15 \mu \mathrm{m}$ ), and a height of 220-230 nm (nominal $220 \mathrm{~nm}$ ); corresponding height profile. b) Square feature with a measured width of $8.9 \mu \mathrm{m}$ (top) and $8.3 \mu \mathrm{m}$ (bottom) (nominal $10 \mu \mathrm{m}$ ), and a height of 220-235 nm (nominal $220 \mathrm{~nm}$ ); corresponding height profile. c) Single line feature with a measured width of $1.6 \mu \mathrm{m}$ (top) and $2.8 \mu \mathrm{m}$ (bottom) (nominal $3 \mu \mathrm{m}$ ), and a height of 220$235 \mathrm{~nm}$ (nominal $220 \mathrm{~nm}$ ); corresponding height profile. d) Single line feature with a measured width of $0.8 \mu \mathrm{m}$ (top) and $1.8 \mu \mathrm{m}$ (bottom) (nominal $2 \mu \mathrm{m}$ ), and a height of about 220 - $280 \mathrm{~nm}$ (nominal $220 \mathrm{~nm}$ ); corresponding height profile. 
Chemicals. Nitric acid (65\%), ortho-phosphoric acid (85\%), acetic acid (100\%), and sodium nitrite (p.a.) were purchased from Merck. Trifluoroacetic acid (99\%), octanol (99+\%), sodium propanesulfonate hydrate $(98 \%)$, sodium pentanesulfonate hydrate (HPLC grade), sodium hexanesulfonate (HPLC grade), sodium heptanesulfonate hydrate (HPLC grade), sodium octanesulfonate hydrate (98\%), sodium decanesulfonate (96\%), sodium dodecanesulfonate (99+\%), sodium tetradecanesulfonate (97\%), and sodium hexadecanesulfonate (HPLC grade) were purchased from Acros. All chemicals were used as received.

Atomic force microscopy (AFM). AFM analysis of etched substrates was performed in non-contact (tapping) mode on a Veeco NanoMan Dimension 3100 scanning probe microscope using an Ultrasharp $\mu$ Mash NSC16 type A cantilever.

Substrate pretreatment. The sputtered $\mathrm{APC} / \mathrm{MoCr}$ glass substrates were rinsed with water, ethanol, and n-heptane and dried in a stream of nitrogen before exposure to a Tepla 300E microwave argon plasma prior to printing. In initial experiments delamination of the metals layers during etching was repeatedly observed. The problem was solved, by employing an $\mathrm{Ar} / \mathrm{H}_{2}$ gas

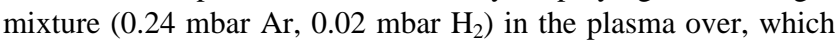
was operated for only short exposure times ( $3 \mathrm{~min}$ ) at low power $(150 \mathrm{~W})$.

Preparation of the etching bath. (Caution! The etching bath must be handled with great care in a fume hood! Skin contact and the inhalation of vapors must be prevented!) It was observed that the preparation procedure of the etchant solution is important for the final etching performance. The optimized preparation procedure comprises the following steps:

(1) mixing, under cooling, trifluoroacetic acid and about two thirds of the total amount of water,

(2) adding, under cooling, nitric acid to the obtained mixture,

(3) mixing sodium nitrite with the remaining amount of water, and

(4) adding, under cooling, the solution obtained in step (3) to the acid-water mixture obtained in step (2),

(5) adding sodium decanesulfonate to the solution obtained in step (4).

Step (1) is very exothermic and it is important that sufficient cooling is provided. Upon addition of the nitrite solution large amounts of nitrogen oxides will be released to the gas phase above the solution, if the mixture has not been cooled to below room temperature before the addition of the nitrite solution. Prior to the addition of nitrite, it is important that sufficient water has been added to the acid mixture to release most of the hydrolysis energy. The nitrite should also not be added as a solid to the acidwater mixture to avoid local high concentrations of nitrite. Following these guidelines for the preparation of the etchant solution, reproducible results were obtained.

Etching procedure. Immediately after printing, substrates were immersed vertically into an etching container $(16 \times 3 \times 12$ $\mathrm{cm}^{3}, \mathrm{~L} \times \mathrm{W} \times \mathrm{H}$ ) containing about $550 \mathrm{~mL}$ of etching solution. Etching was performed at room temperature without stirring or movement of the substrate. After completion, the substrate was removed from the etching bath and immersed quickly in a large volume (about $3 \mathrm{~L}$ ) of deionized water under stirring. The substrates were subsequently rinsed with deionized water and ethanol prior to drying in a stream of nitrogen.

Etching rates. The time to clear (TTC), the time necessary for complete development of the pattern by etching through both metal layers in the unprotected areas, was determined by optical inspection. For the optimized NTW etchant $\left(\mathrm{HNO}_{3}\right.$ (65\%), TFA (99\%), $\mathrm{H}_{2} \mathrm{O}$ (volume fractions: 3:9:13); $\mathrm{NaNO}_{2}\left(10^{-1} \mathrm{M}\right)$; $\left.\mathrm{H}\left(\mathrm{CH}_{2}\right)_{10} \mathrm{SO}_{3} \mathrm{Na},\left(10^{-3} \mathrm{M}\right)\right)$, it was found to be $100 \mathrm{~s}$ for the full
APC/MoCr stack (200/20 nm). Samples with a thinner APC layer (APC/MoCr, 100/20 nm) etched in about $70 \mathrm{~s}$, whereas the etching time for only a MoCr layer $(20 \mathrm{~nm})$ was about $40 \mathrm{~s}$. For comparison, a pure Mo layer of $20 \mathrm{~nm}$ etched in about 20-25 s. Individual etching rates can thus be estimated to be about $3.3 \mathrm{~nm}$ $\mathrm{s}^{-1}$ for APC and $0.5 \mathrm{~nm} \mathrm{~s}^{-1}$ for MoCr.

Etch profile. The profiles of the etched features correspond with the observed small differences of the etching rates for the APC and the MoCr layer. The largest observed overetch at the top of the elevated features is about two times larger than expected for a regular anisotropic etching process. This is most probably a direct consequence of this etching rate difference. A part of the effect may also result from galvanic coupling between the two metal layers. In most cases the edge transition between the two layers was hardly noticeable with a sharp taper (Figs. S7a and b). In the case of smaller features a wider MoCr socket (plus about $0.3-0.5 \mu \mathrm{m}$ on each side relative to the top width) was observed as a shoulder in the height profile (Figs. S7c and d). 